\title{
The Relationship between Iranian EFL Teachers' Personality and Their Teaching Preference
}

\author{
Tooba Mahmoudi \\ Department of English Language, Faculty of Humanities, Islamic Azad University, Marvdasht Branch, Marvdasht, Fars, \\ Iran \\ Mostafa Zamanian \\ Department of English Language, Faculty of Humanities, Islamic Azad University, Marvdasht Branch, Marvdasht, Fars, \\ Iran
}

\begin{abstract}
The present study sought to investigate the relationship between Iranian EFL teachers' personality types and their teaching preferences. Besides, it attempted to take the notion of gender into account. The participants included 100 EFL teachers and university instructors from seven English language institutes in Shiraz, and two universities in Fars Province. Availability sampling was used for this aim. The Myers-Briggs Type Indicator (MBTI) questionnaire and Teaching Activities Preference (TAP) questionnaire were used to collect the data. The design of the study was survey method; so, both descriptive and inferential statistics were used. Based on the analyses undertaken, the following results were obtained: 1) there was a significant relationship between the personality and teaching preference, 2) Male and female EFL teachers' (from Shiraz English language institutes) teaching preferences were statistically the same. The results could be used by teachers, university instructors, syllabus designers and, in general, all groups involved in education.
\end{abstract}

Index Terms - Iranian EFL teachers, teachers' personality, Myers-Briggs Type Indicator (MBTI), teaching preferences

\section{INTRODUCTION}

Nowadays, academic work in every field of study is extensively linked to real world professional experience and teaching is not an exception to this rule. Thus, in order to have well prepared EFL teachers, one needs to provide real life training program for them. With regard to this, a teacher is always influenced by many factors throughout his or her learning. There is an urgent need to know the role of teachers in pedagogical success and their personality factors. In an EFL classroom, a teacher controls over many factors, such as classroom's physical environment, students' moods and behaviors, the amount of communication between teacher and students which in turn will affect not only students' motivation for English language learning but also their environment and behavior. Moreover, it is necessary for language teachers to investigate how their personality type can affect their teaching preference. With this information at hand, the context of foreign language teaching with regard to characteristics of EFL teachers, their pedagogical success and their teaching preference remains challengeable and needs more practical investigation (Rahimi \& Asadollahi, 2012).

Knowing the teachers and their characteristics has become dominant and necessary for better teacher education and pedagogical success in the new educational climate. Research on foreign-language teacher preparation and development has grown toward complexity and sophistication during the last two decades. Knowing teachers' personal and psychological factors is one of the complex areas of teacher preparation and development research (Saha and Dworkin, 2009). Saha and Dworkin (2009), regarding the importance of the issue, consider teachers and their activities for learning processes as the central element at all levels of educational system. Today, teachers are considered as active and decision-makers with different personal characteristics and psychological factors and they are not looked upon as passive figures and only performers of prescribed methods.

Also, gender is one crucial factor which might influence teachers' professional lives in general and their teaching preferences in particular considering their personality and individual characteristics. It is believed that social relations and the dominance of either gender (usually male) affect teachers' lives (Karimvand, 2011). In educational settings, female professionals are usually subordinate to male authorities where professional interactions are usually characterized by marginalization of women (Bartlett, 2005). However, there are few studies which have focused on how gender might affect teachers' choice of different teaching styles the results of which are different (Karimvand, 2011). For instance, Aliakbari and Soltani (2009), in a study of gender differences in Iran, found that Kurdish females prefer active, reflective, sensing, intuitive, verbal and sequential styles except for the visual and global ones. They also found that Persian male EFL teachers and students prefer all styles including active, reflective, sensing, intuitive, visual, verbal, and global except for the sequential one. 
The objective of present research, then, was two-fold in nature: It was in some respects confirmatory and, in others, exploratory. Following research questions were considered to be answered.

Research question 1: Is there any significant relationship between Iranian EFL teachers' personality and their teaching preference?

Research question 2: Do Iranian male or female teachers adopt significantly different teaching preferences?

\section{LITERATURE REVIEW}

Many researches have been carried out so far to investigate the relationship between teaching/learning preference and personality types, either teachers or learners' personality types. For example, Abanador, Buesa, Remo, Mañibo (2014) mentioned "Teaching Methods and Learning Preferences in the Engineering Department of an Asian University", and claimed that this research made an attempt to determine the different methods used by the faculty members and the learning preference of the engineering students that would help in attaining good coordination leading to students' academic learning. Descriptive type of research has been utilized in this study with 100 engineering students as the respondents. The gathered data showed that, professors often used teacher-centered method while content-focused method is considered as the most preferred by the students. From these results, an enhancement program was designed for the students to be able to cope with the teaching styles for their effective learning.

Moreover, in the other study entitled "A Study of Students and Teachers' Preferences and Attitudes towards Correction of Classroom Written Errors in Saudi EFL Context", Hamouda (2011), through using a questionnaire, elaborated Saudi EFL students' and teachers' preferences and attitudes towards written error corrections. The study also aimed at identifying the difficulties encountered by teachers and students during the feedback process. The questionnaire findings of this research revealed that both teachers and students had positive attitudes towards written error correction. The study also showed that while teachers and students share such common preferences as the importance of error correction and the types of errors, there are considerable discrepancies as to the techniques of error correction. For instance, students favor the overall correction, whereas most teachers do not. However, the results showed that students prefer teacher correction to peer and self-correction. Moreover, both the teachers and students encountered a number of difficulties. To solve the problem, some suggestions were investigated.

In another study entitled "Preference-based teaching: Helping students with severe dis-abilities enjoy learning without problem behavior", Reid and Green (2006) examined a paper that described preference-based teaching, a recently developed means of reducing problem behavior by making teaching pro-grams enjoyable for the students. They explain that preference-based teaching begins with actions taken prior to beginning teaching sessions to set the occasion for an enjoyable student experience. A step-wise process subsequently is used to incorporate student preferences within the teaching process. Brief, preferred activities are conducted immediately before initiating a teaching session to enhance student responsiveness to the teacher. Preferred activities are then built into the instructional process (e.g., interspersing easy instructional tasks or brief breaks), and each teaching session is followed by a highly preferred student activity.

In addition to what was mentioned above, the results of some applied researches have supported the efficacy and practicality of enhancing student enjoyment through preference-based teaching, resulting in benefits for both student and teacher. For instance, Ayadi, Chatterjee, and Woldie (2006) attempted to show whether there is any match between students' learning style preferences to performance on four types of examination questions in a study. The results reported in this study showed that intuitive and thinking students did not perform well on open-ended quantitative test. Moreover, intuitive students were not very good when it came to multiple-choice quantitative test. Finally, feeling and sensing students performed better on multiple-choice theory tests.

A number of studies have also been conducted in the Iranian context. For instance, Ebrahimi (2015) in her research entitled "The relationship between EFL teachers' personality traits emotional intelligence and their job satisfaction" attempted to investigate the relationship between personality traits, emotional intelligence, and English teachers' job satisfaction. This study was made on Iranian English as a Foreign Language (EFL) teachers. In so doing, a sample of 80 EFL teachers, who were teaching English in English language institutes in Tehran, Iran was selected. The participants' views towards their job satisfaction, emotional intelligence, and personality traits were investigated using three Likerttype questionnaires. The results of descriptive statistics revealed that Iranian EFL teachers were not satisfied with school-based and system-based factors of their career. Their satisfaction restricted to the intrinsic factors of their job. The results of multiple regression analyses showed that the personality traits are stronger predictors of teachers' job satisfaction. the study added the potential influence of the personality and emotions in promoting teachers' job satisfaction and a sense of belonging and belief in positive outcomes.

In another study with the title of "The Relationship between Iranian EFL learners' and instructors' personality type and error correction Preferences" written by Ranjbar, Zamanian (2014) the effect of personality type on individuals' preferences for corrective feedback on writing was examined. It also intended to find if there is any significant relationship between the most preferred aspect, type, and source of corrective feedback and the participants' personality type. To this end, three questions were posed and three instruments were used. The necessary data were collected from 41 EFL female students and 9 male teachers of some well-known institutes in Shiraz. The results of the study revealed that there is no significant relationship between personality type and participants' opinions about method, delivering 
agent of error correction as well as aspect of language to be corrected. According to the results of the study both teachers and students agree $d$ that grammatical error in writing should be more focused and the most favored type of corrective feedback was error identification which supplies the correct form and ex planation. But teachers and students opinions regarding the source of error correction were different, the students preferred to be corrected by their teachers while the teachers wanted their students to correct their own mistakes.

A study by Behnam and Bayazidi (2013) attempted to investigate the relationship between personality type of teachers and teaching styles in TEFL Iranian adult context. Forty teachers who participated in this study were teaching IELTS or TOFEL to adult students, over 23. The Mayer and Brigs Type Indicator (MBTI), an instrument based on Jung's personality theory and Grasha-Reichmann Teaching Style Inventory (TSI) were used. Descriptive method and SPSS were applied to get accurate results. The results showed that personality type was not a significant predictor of teaching style. The gender of teachers, moderator variable, showed no effect on teaching style either (as cited in Rauf, 2017).

Gholami, and Gholami (2013) also carried out their study based on Job- Personality theory of Holland and in order to study the personality type of the principals and its relation with job satisfaction of teachers. The hypotheses of the research included. 1- There is relation between the personality type of principals and teachers. 2- There is relation between the personality type of principals and satisfaction of the teachers. 3-the conforming types of principals and teachers have a larger degree of satisfaction as compared with non-conforming types of teachers and principals. 4- Job satisfaction parameters (job success, job compatibility and job motivation) in conforming group is different from that of conforming group. The statistical society of research covered all the teachers and principal in girls high schools of districts 1 and 2 of Eslamshahr which comprised 240 teachers and 20 principals from 20 high schools selected on random sampling method. By the use of research tools (SDS) of Holland and job satisfaction of Berifield and Routh, required information on the above hypotheses was gathered and by the use of statistical tests and Pirrson's correlation coefficient; the information were analyzed. After testing the hypothesis, the first hypothesis was approved and the 2,3 and 4 hypothesis was refused.

Finally, Alibakhshi (2011) in his article "On the Impacts of Gender and Personality Types on Iranian EFL Teachers' Teaching Efficacy and Teaching Activities Preferences" analyzed the impacts of personality and gender on Iranian English teachers' teaching activities preferences and their teaching efficacy. To accomplish this, 280 male and female English language teachers participated in the study. Myers -Briggs Type Indicator (MBTI), teaching efficacy, and teaching activities preference questionnaires were used. To analyze the data, descriptive statistics and Two ANOVA tests were used. The results of the study showed that ESTJ (extroverted, sensing, thinking, and judging) and ISTJ (introverted, sensing, thinking, and judging) were predominant personality types among Iranian EFL teachers. Results also indicated that both male and female teachers with different personality types have the same sense of teaching efficacy. It was also revealed that gender and personality influence teachers' teaching activities preferences

\section{MethODOLOGY}

\section{A. Participants}

The participants in this study included 100 EFL teachers from 9 English language institutes in Shiraz, south of Iran. Both university instructors and language teachers (from language institutes) were used. The universities and language institutes from which the participants were extracted were as follows: Shiraz Azad University, Marvdasht Azad University and 7 English language institutes including Niayesh, Sobhan, Puyesh, Omid, Andishee Bartar, Nasim and Keyhan. The participants were selected through availability sampling. Both males and females were included in the study. Some demographic information including level of education (B.A., M.A., and Ph.D.), gender, etc. were also included in the questionnaires.

\section{B. Instruments}

To start, two instruments were used in this study, 1) The Myers-Briggs Type Indicator (MBTI) questionnaire and, 2) Teaching Activities Preference (TAP) questionnaire. Each of them have been explained completely below.

\section{The Myers- Briggs Type Indicator (MBTI) Questionnaire}

To start with, as teachers' personality is the most important factor in this study, a psychological test called MBTI which is prepared by Katharine C. Briggs and Isabel Briggs Myer (1975) was given to them in order to indicate MBTI is one of the most widely used psychological tests administrated today and its main objective is to identify basic personal preferences. It groups teaching activities in eight teaching styles: Extroverts, introverts, sensing, intuitive, thinking, judging, perceiving, and feeling types. The questionnaire included 64 items to be rated on a 5-point Likert scale, whereby " 1 " meant "I don't agree with the statement at all" and " 5 " meant "I fully agree with the statement". For the sake of validity, the researcher used the help of two experts, each with a Ph.D. degree in TEFL. The experts checked the whole content of the questionnaire and commented on it. And also this questionnaire was used before in some cases. To check the reliability of the questionnaire, the reliability of the personality (MBTI) questionnaire based on Cronbach's Alpha was found to be 0.861 which was high and convenient (above 0.7 ).

\section{Teaching Activities Preference (TAP) Questionnaire}


This questionnaire was developed by Cooper (2001) to see how EFL teachers rate a variety of teaching activities in teaching English. He designed the Teaching Activities Preference (TAP) questionnaire to include activities that appeal to specific personality dimensions (Lawrence, 1997, pp. 47-80; Myers \& Myers, 1998, p. 265). The questionnaire includes 20 items to be rated on a 5-point Likert scale, whereby "1" meant "I don't agree with the statement at all" and "5" meant "I fully agree with the statement". For the sake of validity, the researcher used the help of two experts, each with a Ph.D. degree in TEFL. The experts checked the whole content of the questionnaire and commented on it. And also this questionnaire was used before in some other cases. To check the reliability of the questionnaire, the Teaching Activities Preference, it was 0.640 which was acceptable. This indicated that both questionnaires were reliable.

\section{Data Collection Procedure}

To undertake the study, first MBTI, and TAP were administered to 100 EFL teachers at Shiraz English language institutes and two universities. Prior to completion of the questionnaires, the researcher provided the participants with some information on the objectives of the research and on how to complete the questionnaires. Then, the data were extracted from the questionnaires and fed into SPSS (Version 21) for further statistical analysis.

\section{DATA ANALYSIS AND DISCUSSION}

In order to analyze the collected data, both descriptive (in the form of frequency counts, tables and figures) and inferential statistics (correlation coefficient, independent t-test) were used to answer the questions formulated earlier in this study. The results of these analyses are reported in details in the following part.

\section{A. Demographic Information}

In this section, in order to detect the factors examined in this study, and before addressing the findings related to the research hypotheses, some descriptive data of the study is given. It should be noted that the purpose of this study was, "The relationship between Iranian EFL teachers' personality and their teaching preference" According to this, the independent variable was "teachers' personality".

The sample participants of the present study consisted of 100 EFL teachers (from Shiraz English language institutes) and university instructors (from Marvdasht and Shiraz Azad University) as presented in Table 1.

TABLE 1.

DISTRIBUTION OF GENDER

\begin{tabular}{||l|l|l|}
\hline Gender Statistics & Frequency & Percent \\
\hline Female & 62 & 62.0 \\
\hline Male & 38 & 38.0 \\
\hline Total & 100 & 100.0 \\
\hline
\end{tabular}

As can be seen in Table 1, most of participants were females. Males (38 persons out of $100(38 \%)$ ) and females (62 persons out of $100(62 \%)$ ). This can better observed in the following figure.

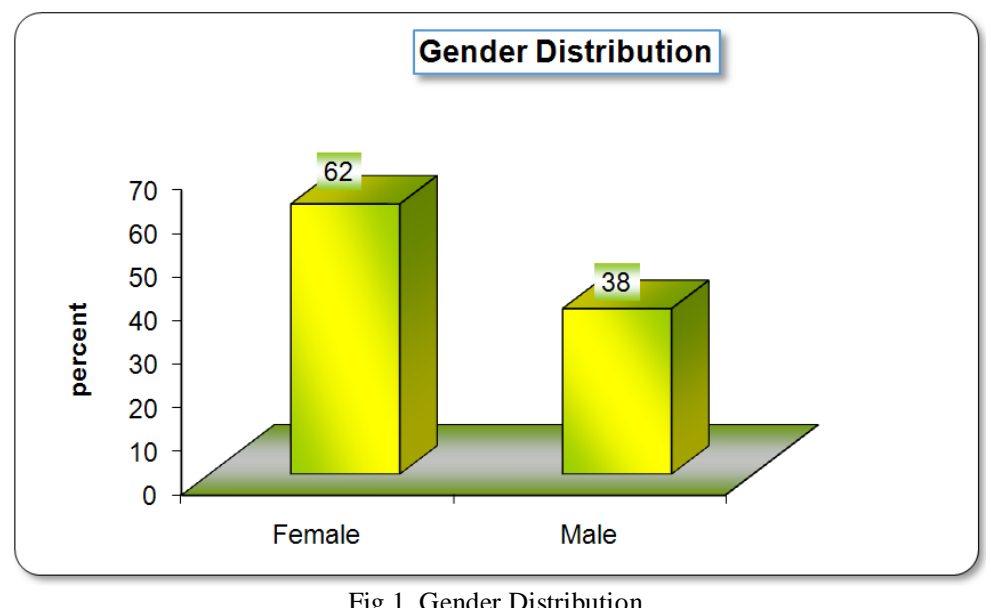

Fig.1. Gender Distribution

As seen in Figure 1, most of the participants were females. Males (38 persons out of $100(38 \%)$ ) and females (62persons out of $100(62 \%))$. 
TABLE 2.

DISTRIBUTION OF EDUCATIONAL LEVEL

\begin{tabular}{|c|c|c|}
\hline $\begin{array}{ll}\text { Degree } & \text { Statistics } \\
\end{array}$ & Frequency & Percent \\
\hline BA & 29 & 29.0 \\
\hline MA & 58 & 58.0 \\
\hline $\mathrm{PhD}$ & 13 & 13.0 \\
\hline Total & 100 & 100.0 \\
\hline
\end{tabular}

Table 2 showed distribution of participants based on level of education. As indicated in Table 2, out of the 100 participants in this study, 29 (29\%) had a BA degree while 58 (58\%) held an MA degree. Finally, 13 (13\%) participants held a PhD degree. Hence, the majority of the participants held an MA degree.

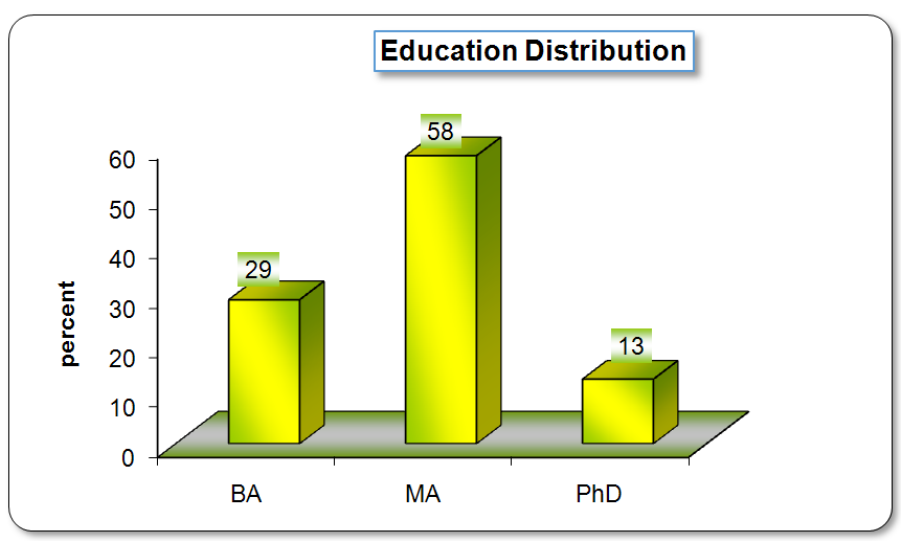

Fig. 2. Distribution of Educational Level

Figure 2 shows distribution of participants based on level of education. In the following part, descriptive statistics can be observed.

\section{B. Descriptive Statistics}

The following table illustrates information related to personality and Iranian teachers' teaching preferences.

TABLE 3.

STATISTICS FOR PERSONALITY AND TEACHING PREFERENCE

\begin{tabular}{|c|c|c|c|c|c|c|c|c|}
\hline Variable & Group & $\mathrm{N}$ & Mean & Std. Deviation & Skewness & Kurtosis & Minimum & Maximum \\
\hline \multirow{6}{*}{ Personality } & Female & 62 & 221.85 & 18.119 & 0.078 & 0.288 & 170 & 259 \\
\hline & Male & 38 & 223.97 & 27.335 & 0.308 & 0.859 & 163 & 289 \\
\hline & BA & 29 & 218.86 & 19.826 & -0.223 & 1.889 & 163 & 259 \\
\hline & MA & 58 & 224.19 & 24.031 & 0.426 & 0.868 & 165 & 289 \\
\hline & $\mathrm{PhD}$ & 13 & 224.31 & 16.499 & -0.277 & 1.481 & 189 & 257 \\
\hline & Total & 100 & 222.66 & 21.968 & 0.300 & 1.251 & 163 & 289 \\
\hline \multirow{6}{*}{$\begin{array}{l}\text { Teaching } \\
\text { Preference }\end{array}$} & Female & 62 & 79.29 & 6.522 & -0.004 & -0.119 & 64 & 95 \\
\hline & Male & 38 & 78.05 & 5.652 & -0.077 & -1.026 & 67 & 88 \\
\hline & BA & 29 & 78.52 & 5.488 & 0.686 & -0.094 & 70 & 91 \\
\hline & MA & 58 & 78.34 & 6.345 & -0.065 & -0.181 & 64 & 95 \\
\hline & $\mathrm{PhD}$ & 13 & 81.62 & 6.813 & -0.803 & 0.520 & 67 & 92 \\
\hline & Total & 100 & 78.82 & 6.206 & 0.016 & -0.313 & 64 & 95 \\
\hline
\end{tabular}

Table 3 represents statistics for variables Personality and Teaching Preference in different groups. Results indicated that the Personality mean was 222.66 with a standard deviation of 21.968 , ranged between 163 and 289. The Skewness was 0.3 , in the accepted range (between -1 and 1 ). The Kurtosis was 1.251 a little above the range. It shows there might be violation of normal distribution. The latter was checked explicitly by the Kolmogorov-Smirnov Test in the next section.

Mean of Teaching Preference was 78.82 with a standard deviation of 6.206, ranged between 64 and 95 . The Skewness and Kurtosis were 0.016 and -0.313 , respectively, in the accepted range (between -1 and 1).

\section{Inferential Statistics}

In this section, each research hypothesis had tested either by parametric or by non-parametric statistical tests (correlation coefficient, independent t-test). The parametric tests were more precise but they required that the distribution of the variable be normal. For this reason, the normality of the variable distribution was investigated for different gender and educational level groups by the Kolmogorov-Smirnov Test. 
TABLE 4.

KOLMOGOROV-SMIRNOV TEST OF NORMALITY FOR PERSONALITY AND TEACHING PREFERENCE

\begin{tabular}{||l|l|l|l|l||}
\hline \multirow{2}{*}{ Groups } & Personality & \multicolumn{2}{|l|}{ Teaching Preference } \\
\cline { 2 - 5 } & Z & Sig. & Z & Sig. \\
\hline Female & 0.578 & 0.892 & 0.700 & 0.711 \\
\hline Male & 0.826 & 0.502 & 0.780 & 0.577 \\
\hline Total & 0.996 & 0.275 & 0.797 & 0.549 \\
\hline
\end{tabular}

Table 4 showed results of the Kolmogorov-Smirnov Test. Since the $\mathrm{p}$-values were greater than 0.05 ( $\mathrm{p}>0.05)$ for all variables (Personality and Teaching Preference) and in all groups (male, female and total), the statistics were not significant which meant that the distributions were normal. Thus, the researcher could use parametric tests to analyze the research questions of the study. In what follows, each research hypotheses will be repeated and all the analyses pertaining to that hypothesis will be provided.

Research Question 1: Is there any significant relationship between Iranian EFL teachers' personality and their teaching preference?

The scoring system used for the questionnaire was based on the Likert scale. The participants could choose one of the options 1, 2, 3, 4 or 5. To investigate this hypothesis, Pearson's correlation test was used as presented in Table 4.5.

TABLE 5

PEARSON CORRELATION BETWEEN PERSONALITY AND TEACHING PREFERENCE

\begin{tabular}{|c|c|c|c|}
\hline $\begin{array}{ll}\text { Variables } & \text { Statistics } \\
\end{array}$ & Pearson Correlation & Sig. & $\mathrm{N}$ \\
\hline personality and teaching preference & 0.478 & 0.000 & 100 \\
\hline
\end{tabular}

As presented in Table 5, the correlation between WTC and EI was significant at the level of 0.01. Thus, there was a significant relationship between personality and teaching preference. The Pearson correlation was 0.478 which is a positive correlation. Two variables were directly correlated, since the correlation was positive. It meant that the personality trait increased with an increase in the teaching preference. This approved hypothesis 1 . Hence, the first hypothesis of the study, "There is a relationship between Iranian EFL teachers' personality and their teaching preference." was accepted.

Research Question 2: Do Iranian male or female teachers adopt different teaching preference?

To answer this research question, the independent $t$-test was used as presented in Table 4.6.

TABLE 6.

THE INDEPENDENT T-TEST FOR COMPARISON OF TEACHING PREFERENCE BETWEEN MALES AND FEMALES

\begin{tabular}{||l|l|l|l|l|l|l|l|l|l|}
\hline \begin{tabular}{|l|l|l|l|l|l|} 
Variable Statistics \\
female
\end{tabular} & $\mathrm{N}$ & Mean & Std. Deviation & $\begin{array}{l}\text { Std. Error } \\
\text { Mean }\end{array}$ & $\begin{array}{l}\text { Mean } \\
\text { Difference }\end{array}$ & T \\
male & 62 & 79.29 & 6.522 & 0.828 & 1.238 & 0.968 & 98 \\
\hline
\end{tabular}

The result of independent t-test as presented in Table 6 showed that there was no significant difference between males and females in teaching preference $(\mathrm{p}>0.05)$. This indicated that males and females teaching preferences were statistically the same. Thus, the second research hypothesis of the study, i.e. "Male and female teachers adopt significantly different teaching preferences." was rejected.

\section{CONCLUSION}

In this part, each major finding of the study will be discussed under a separate heading. Since, there were two research questions, the results will be discussed under two headings.

Discussion on the first research question: The first research question of the study was, "Is there any significant relationship between Iranian EFL teachers' personality and their teaching preference?" the results of Pearson's correlation test, indicated in Table 4.5, revealed that the correlation between WTC and EI was significant at the level of 0.01 . Thus, there was a significant relationship between personality and teaching preference.

The Pearson correlation was 0.478 which is a positive correlation. Two variables are positive correlated, since the correlation is positive. It means that the personality trait increases with an increase in teaching preference. This approves hypothesis 1. Hence, the first hypothesis of the study, "There is a relationship between Iranian EFL teachers' personality and their teaching preference." was accepted. This finding was in line with the resulted reported by Alibakhshi (2011) who showed that ESTJ (extroverted, sensing, thinking, and judging) and ISTJ (introverted, sensing, thinking, and judging) were predominant personality types among Iranian EFL teachers.

The second research question of the study was, "Do Iranian male or female teachers adopt different teaching preference?" The result of the independent t-test as presented in Table 4.6 showed that there was no significant difference between males and females in their teaching preference $(p>0.05)$. This indicated that males and females teaching preferences were statistically the same. Thus, the second research hypothesis of the study, "Male and female 
teachers adopt significantly different teaching preferences." was rejected. Similarly, this finding was supported by the findings reported by Alibakhshi (2011) who reported that both male and female teachers with different personality types had the same sense of teaching efficacy. It was also revealed that gender and personality influenced teachers' teaching activities preferences.

All in all, regarding the first question, correlation was correlated between WTC and EI which was significant at the level of 0.01 . Thus, there was a positive relationship between personality and teaching preference. Those variables were directly correlated, since the correlation was positive. It means that an increase in the personality trait could lead to an increase in the teaching preference. For the second research question, the result of independent t-test as presented in Table 4.6 revealed that there was no significant difference between males and females in teaching preference. This indicated that males and females teaching preferences were statistically the same.

\section{Implications and limitations of the Study}

Today, academic work in every field of study is extensively linked to real world professional experience and teaching is not considered as exception to this rule. Thus, if we want to have well prepared EFL teachers, use should provide real life training programs for them. Concentrating on the issue of learning, a teacher is always influenced by many factors throughout his or her learning. It does not matter how old the learner is. The teacher learns or boosts his or her learning through the environment.

First, it not only verifies the efficiency of teachers' personality and their teaching preference in real practice, but it makes an attempt to consolidate the theoretical bases of the approach and provide evidence both for its dependability and credibility. Second, the findings can be insightful for teachers and practitioners as well as the researchers and scholars undertaking research in second language pedagogy. Language schools and universities, particularly, may enjoy the findings of the present study in designing syllabi and evaluation. Educators can benefit from the results in that they can adapt them to their own practices in classrooms, their own lesson plans and even the syllabi and course examinations.

In the present research, the researcher faced a number of limitations a brief account of which has been provided below. Firstly, due to time limitation only two independent variables, namely gender and teachers' personality, were included in the study. Secondly, seeking the cooperation of teachers in some institutes was really a hectic job for which reason availability sampling was used to select the participants in this study. This sampling technique has its own drawbacks and one of them is limited generalizability. Had the researcher used other more objective sampling techniques, the results could possibly have changed.

The third limitation this study was faced with was that only Myers-Briggs Type Indicator (MBTI) questionnaire and 2) and Teaching Activities Preference (TAP) questionnaire were used to collect the data from the participants. Had the researcher added other instruments as well, more interesting results could have been obtained.

\section{Suggestions for Further Research}

Using the findings reported in the present study, other interested researchers can undertake other researches few samples of which have been listed below:

Further researchers can duplicate the present research with extra independent variables, e.g. social class, types of motivation, the teachers' mother tongue, etc. They can use other tools like semi-structured interviews or even include sort of treatment in their study.

Future studies can collect information from both teachers and students. For this purpose, of course, a modified version of the questionnaire would be required. In addition, since the present study was undertaken among EFL teachers, other researchers could make a comparative study between EFL and ESL teachers or between EFL and Native-speaker teachers.

\section{REFERENCES}

[1] Abanador, J. R., Buesa, G. C. D., Remo G. M. L., Mañibo, J. (2014). Teaching methods and learning preferences in the engineering department of an Asian university. International Journal of Academic Research in Progressive Education and Development, 3(1), 1-15.

[2] Alibakhshi,. G. (2011). On the Impacts of Gender and Personality Types on Iranian EFL Teachers' Teaching Efficacy and Teaching Activities Preferences. Iranian Journal of Applied Linguistics (IJAL), 14(1), 1-22.

[3] Aliakbari, M., \& Soltani, N. (2009). Variation of learning styles among Iranian EFL learners: Effects of culture, language background and gender. In Proceedings of the 16th Conference of Pan-Pacific Association of Applied Linguistics (pp. 200-209).

[4] Ayadi, O. F., Chatterjee, A., \& Woldie, M. (2006). Matching testing strategy with student personality in a historically Black University [Abstract]. Journal of College Teaching \& Learning, 3(3) pp. 87-93

[5] Bartlett, A. (2005). "She Seems Nice": Teaching Evaluations and Gender Trouble. Feminist Teacher, 15, (3), 195-202.

[6] Behnam, B. and M. Bayazidi (2013). "The relationship between personality types and teaching styles in Iranian adult TEFL context." Global Journal of Foreign Language Teaching 2.(2) pp. 21-32.

[7] Ebrahimi, Sh. (2015). The relationship between EFL teachers' personality traits emotional intelligence and their job satisfaction. IJLLALW, 9(2), 156-163.

[8] Fazeli, H. (2012). The influence of personality traits on the use of Memory English Language Learning Strategies. Indian Journal of Science and Technology, 5(7), 3041-3046.

[9] Gholami, Z., Gholami, N. (2013). The relationship between personality type of teachers and administrators, and teachers' satisfaction (based on Holland's theory). International Journal of Advanced Studies in Humanities and Social Science, 1(1), 49- 
60.

[10] Hamouda, A. (2011). A study of students and teachers' preferences and attitudes towards correction of classroom written errors in Saudi EFL context. English Language Teaching. 4(3), 128-141.

[11] Karimvand, P. N. (2011). The nexus between Iranian EFL teachers' self-efficacy, teaching experience and gender. English Language Teaching, 4(3), pp.171-183.

[12] Rahimi, M., Asadollahi, F. (2012). On the relationship between Iranian EFL teachers' classroom management orientations and teaching style. Procedia - Social and Behavioral Sciences 31 (2012) 49 - 55.

[13] Ranjbar, S., Zamanian, M. (2014). The Relationship between Iranian EFL learners' and instructors' personality type and error correction preferences. Journal of Studies in Learning and Teaching English 2(5), 79-97.

[14] Rauf, W., (2017). Students' Perception towards the Lecturer's Teaching Styles and Personality Traits at Muhammadiyah University of Makassar. An MA thesis: available at: eprints.unm.ac.id/5693/1/Wahyuddin\%20Rauf.pdf.

[15] Reid, D.H., \& Green, C.W. (2006). Preference-based teaching: Helping students with severe dis-abilities enjoy learning without problem behavior. TEACHING Exceptional Children Plus, 2(3) Pp. 1-11.

[16] Saha, L. J., \& Dworkin, A. G. (2009). Teachers and Teaching in an Era of Heightened School Accountability: A Forward Look. In International Handbook of Research on Teachers and Teaching (pp. 1177-1185). Springer US.

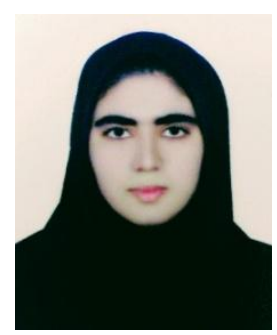

Tooba Mahmoodi was born in Larestan, Iran on April 22, 1990. She holds an MA in English Language Teaching from Azad University of Marvdasht, Shiraz, Iran. She lives in Shiraz and received her BA in English Language and Literature from the Zand Institute of Higher Education, Shiraz, Iran in 2015. Her main areas of interest include Linguistics, Pragmatics and English Language and Literature.

Mostafa Zamanian was born in Kazeroon, Iran on 1955. He holds a PhD in English Teaching, from USA. He received his BA and MA in the field from USA, in English Teaching. Besides teaching various courses of EFL at some universities, he is the assistant professor of English in Islamic Azad university of Marvdasht. His main areas of interest include English literature, linguistic. He has got 30 more papers published in the field. 